\title{
Quantitative determination of airborne redox-active compounds based on heating induced reduction of gold nanoparticles
}

Ranxue Yu ${ }^{1,2,3}$, Fei Pan $^{4}$, Claudia Schreine ${ }^{3}$, Xinhou Wang ${ }^{1}$, David M. Bell ${ }^{5}$, Guangyu Qiu* $^{*}, 3$, Jing Wang ${ }^{*}, 2,3$

1. Key Laboratory of Textile Science and Technology of Ministry of Education, College of Textiles, Donghua University, Shanghai, 201620 China

2. Institute of Environmental Engineering, ETH Zurich, 8093 Zurich, Switzerland

3. Advanced Analytical Technologies, Empa, Ueberlandstrasse 129, 8600 Dübendorf, Switzerland

4. Laboratory for Biointerfaces, Empa, 9014 St. Gallen, Switzerland

5. Paul Scherrer Institute, Laboratory of Atmospheric Chemistry, 5232 Villigen, Switzerland

* Corresponding authors: gqiu@ethz.ch (Guangyu Qiu);

jing.wang@ifu.baug.ethz.ch (Jing Wang) 


\section{Table of Content}

S1 Chemicals

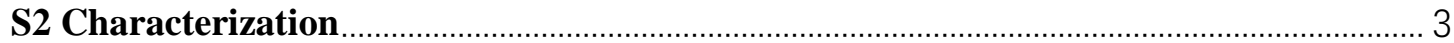

S3 Aerosol sampling, collection and preparation.

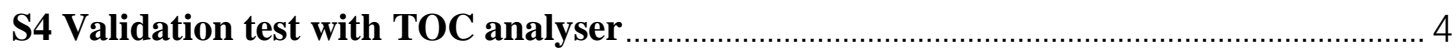

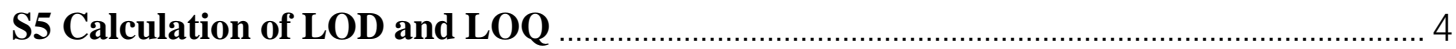

Figure S1. FTIR spectra of SRFA, HA and real-world environmental samples......................... 5

Figure S2. TEM images of the AuNPs as a function of $\mathrm{NaOH}$ concentration ............................ 5

Figure S3. The photographs of solution of AuNPs using by SRFA and HA in the absence of $\mathrm{NaOH}$

Figure S4. Effect of $\mathrm{NaOH}$ concentration

Figure S5. The $\mathrm{pH}$ dependence of the reaction solution before reaction and after the synthesis of AuNPs.

Figure S6. The UV-vis spectra of the AuNPs as a function of the $\mathrm{HAuCl}_{4}$ concentration........ 8

Figure S7. Effect of $\mathrm{HAuCl}_{4}$ concentration

Figure S8. TEM images of the AuNPs as a function of $\mathrm{HAuCl}_{4}$ concentration. ....................... 9

Figure S9. Effect of heating temperature on the formation of AuNPs ......................................10

Figure S10. Time-resolved evolution of absorption of AuNPs ……………………....................10

Figure S11. Calibration curve (a) and (b) corresponding to HA and SRFA ranging from 0.005

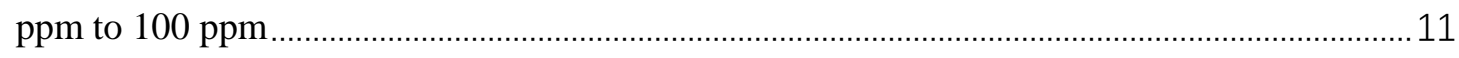

Figure S12. The absorption spectra toward the monthly samples ............................................. 14

Figure S13. TEM images of the AuNPs formed by Basel, Bern, Rigi Mountain and HS .......15

Figure S14. The hydrodynamic size of AuNPs prepared by real-world environmental samples

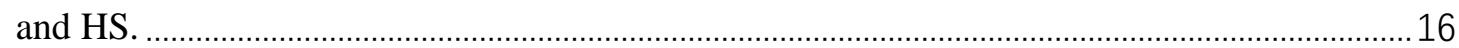

Figure S15. Comparison of AuNPs intensity in the condition of four reductants ....................16

Table S1 The responses data for LOD and LOQ calculation. ................................................ 17

Table S2 Analytical figures of merit of calibration with HA and SRFA ..................................17

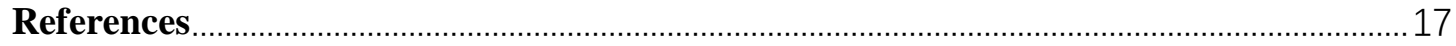




\section{S1 Chemicals}

Gold (III) chloride solution (99.99\%), sodium hydroxide and humic acid were purchased from Sigma (St. Louis, Mo). Suwanee river fulvic acid (SRFA, Standard III) was obtained from International Humic Substances Society (USA). All chemicals were in analytical grade and used without further purification.

\section{S2 Characterization}

The absorbance spectra were recorded in the range of $400-800 \mathrm{~nm}$ at room temperature using a UV-vis spectrophotometer (CARY 1E). The size distribution of AuNPs were further analyzed by dynamic light scattering (DLS) using a Zetasizer Nano Series (Malvern Instruments) instrument. Diluted gold colloidal solutions were dropped onto copper grids covered with an amorphous carbon film to prepare specimens for characterizing the morphologies, diffraction pattern, element imaged by transmission electron microscopy (TEM) with accelerating voltage $150 \mathrm{KV}$ (JEOL JEM2200FS). FT-IR absorption spectra were measured at room temperature on a FTIR instrument (Cary 640) using attenuated total reflection (ATR) mode. The spectra resolution was 2 $\mathrm{cm}^{-1}$ and 64 scans were averaged.

\section{S3 Aerosol sampling, collection and preparation.}

The sampling station in Bern was near the traffic roadside which had approximately 20,000 vehicles passing by every day. The sampling site was $4 \mathrm{~m}$ away from the road and surrounded by high-rise buildings. Another sampling station in the suburban of Basel was located in a quiet park with high green coverage rate. The last station in Rigi was situated on Rigi Mountain above 1000 m.a.s.l with a high-altitude and rural atmospheric environment.

A high-volume sampler (DH-80, Digitel) was used to collect particles less than $10 \mu \mathrm{m}$ in aerodynamic diameter (PM 10) on the prebaked quartz filters. The sampling flow rate was $500 \mathrm{~L} / \mathrm{min}$. After sampling, all filters were stored in a freezer at $-20{ }^{\circ} \mathrm{C}$ until analysis. With a puncher, portions of filters about $490 \mathrm{~mm}^{2}$ were extracted and daily particulate matter samples from each month were pooled together to represent every month. Portions of the filters were extracted with $1 \mathrm{ml}$ water in a shaker with a speed of $1000 \mathrm{rpm}$ for $30 \mathrm{~min}$ and then extracted specimen were centrifuged at $3500 \mathrm{rpm}$ to remove insoluble suspensions. The supernatants were stored in a freezer at $-20^{\circ} \mathrm{C}$ until analysis. 


\section{S4 Validation test with TOC analyser}

The TOC analyzer possesses a detection limit of $0.05 \mathrm{ppm}$. The samples were treated with hydrochloric acid and sparged with oxygen to drive off inorganic carbon before measurement. Then they were combusted at $680^{\circ} \mathrm{C}$ in oxygen followed by detection of $\mathrm{CO}_{2}$ in a non-dispersive infrared detector. The concentration of HS-equivalent concentration was obtained according to calibration curve using standard solutions of potassium hydrogen phthalate. The samples were measured three times and average value was used in this work.

\section{S5 Calculation of LOD and LOQ}

To get the LOD and LOQ of AuNP sensor, the IUPAC-recommended methodology for spectroscopic methods based on signal-to noise ratio were used. ${ }^{1}$ Firstly, the absorbance of blank samples containing aqueous $\mathrm{HAuCl}_{4}$ and $\mathrm{NaOH}$ solution without $\mathrm{HS}$ were measured for three times. Then, the average absorbance (average blank) along with the associated standard deviation (SD blank) of the blank samples were obtained. SD blank was assigned to the noise $(\mathrm{N})$. Next, a known-concentration of samples were reacted with $\mathrm{HAuCl}_{4}$ and $\mathrm{NaOH}$. The associated absorbance at the maximum wavelength was measured for three times and average absorbance values of samples (average sample) were obtained. Finally, according to equal $1, \mathrm{~S} / \mathrm{N}$ was calculated.

$\mathrm{S} / \mathrm{N}=($ average sample - average blank $) / \mathrm{SD}$ blank

The LOQ was defined as the lowest concentration tested that the differential colorimetric response (absorption peak height) is three times greater than the standard deviations (SD) of the blank measurement. In addition, the LOQ refers to the lowest concentration at which the analyte can be quantitated at defined levels for imprecision and accuracy (bias). It was defined the lowest concentration where the differential colorimetric response is ten times greater than SD of the blank measurement. 


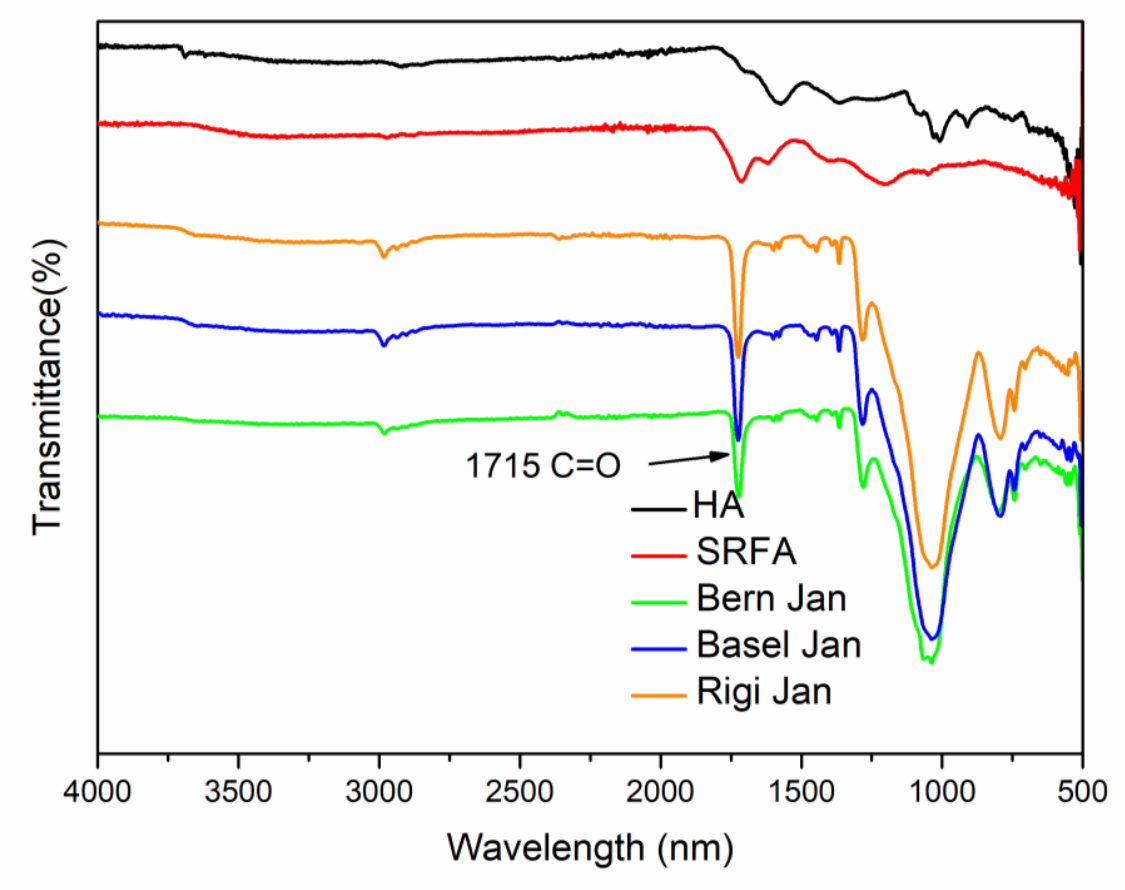

Figure S1. FTIR spectra of SRFA, HA and real-world environmental samples.

(a)

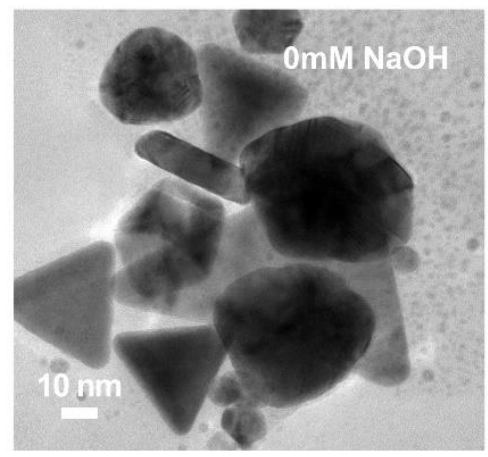

(c)

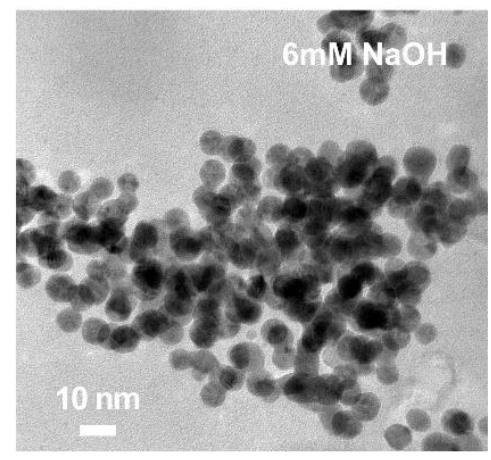

(b)

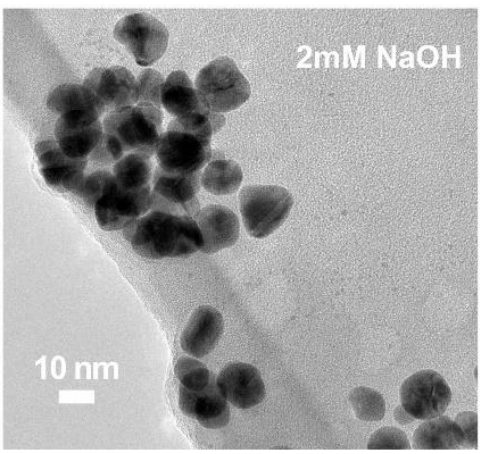

(d)

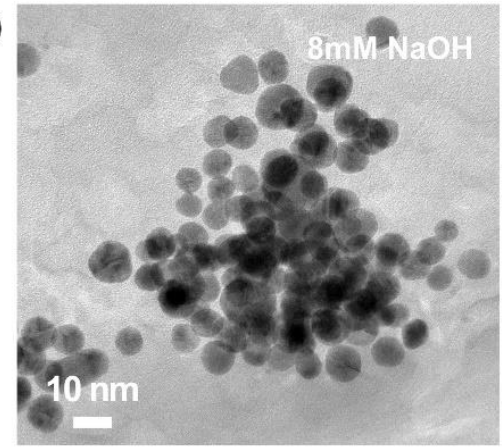

Figure S2. TEM images of the AuNPs as a function of $\mathrm{NaOH}$ concentration. Reduction condition: $\mathrm{c}(\mathrm{SRFA})=100 \mathrm{mg} \cdot \mathrm{L}^{-1}, \mathrm{c}\left(\mathrm{HAuCl}_{4}\right)=1 \mathrm{mM}, \mathrm{c}(\mathrm{NaOH})=0-8 \mathrm{mM}$ (in the final solution), $\mathrm{T}=100^{\circ} \mathrm{C}, \mathrm{t}=40 \mathrm{~min}$. The scale bar is $10 \mathrm{~nm}$. 


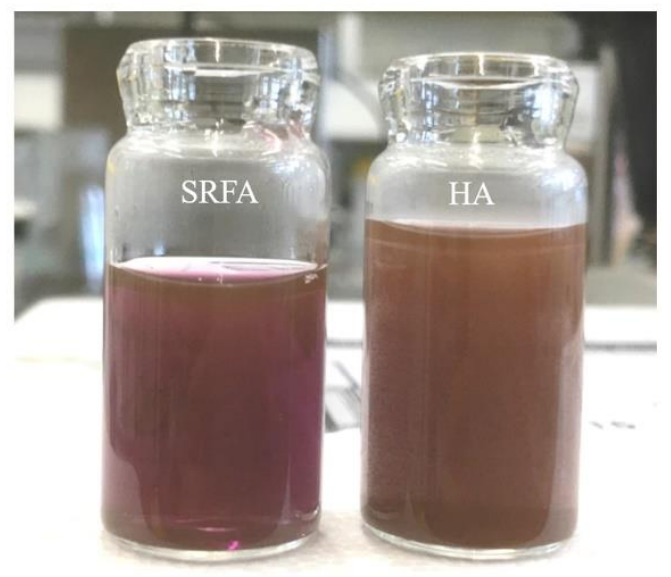

Figure S3. The photographs of solution of AuNPs using by SRFA and HA in the absence of $\mathrm{NaOH}$
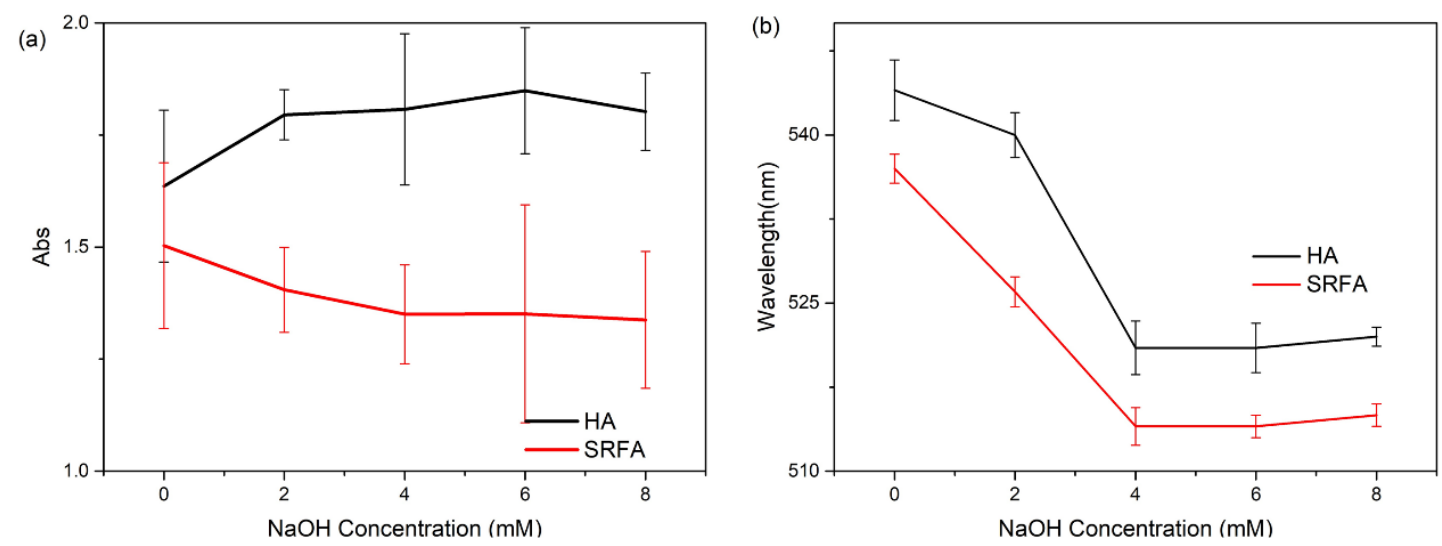

Figure S4. Effect of $\mathrm{NaOH}$ concentration on (a) absorbance intensity and (b) the maximum absorbance wavelength of AuNPs. The error bars represent the standard deviations for three replicates. Reduction condition: $\mathrm{c}(\mathrm{HS})=100 \mathrm{mg} \cdot \mathrm{L}^{-1}, \mathrm{c}\left(\mathrm{HAuCl}_{4}\right)=1$ $\mathrm{mM}, \mathrm{c}(\mathrm{NaOH})=0-8 \mathrm{mM}$ (in the final solution), $\mathrm{T}=100^{\circ} \mathrm{C}, \mathrm{t}=40 \mathrm{~min}$. 


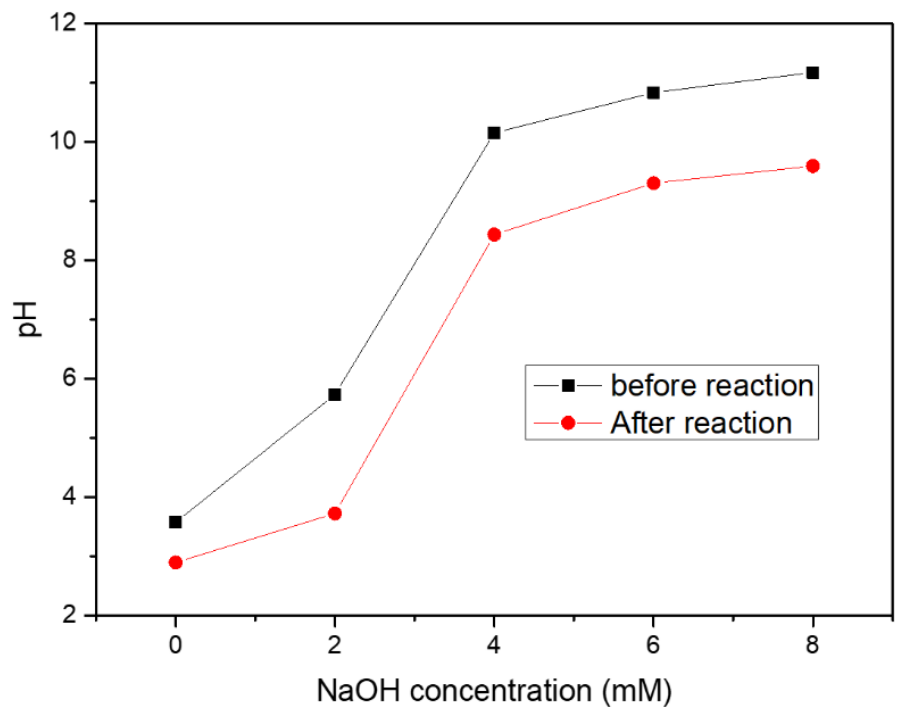

Figure S5. The $\mathrm{pH}$ dependence of the reaction solution before reaction and after the synthesis of AuNPs. Reduction condition: $\mathrm{c}(\mathrm{HS})=100 \mathrm{mg} \cdot \mathrm{L}^{-1}, \mathrm{c}\left(\mathrm{HAuCl}_{4}\right)=1 \mathrm{mM}$, $\mathrm{c}(\mathrm{NaOH})=0-8 \mathrm{mM}$ (in the final solution), $\mathrm{T}=100^{\circ} \mathrm{C}, \mathrm{t}=40 \mathrm{~min}$. 

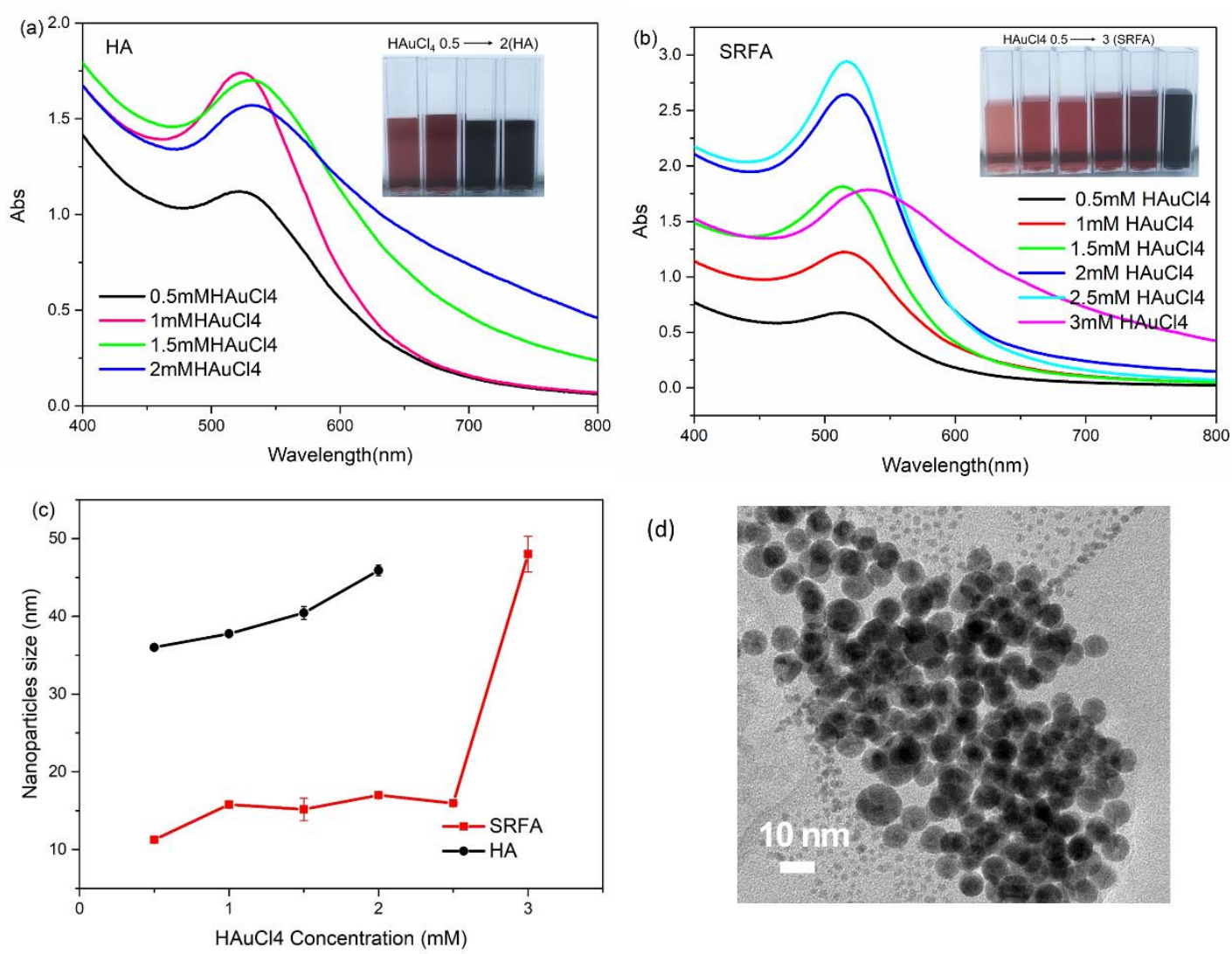

(d)

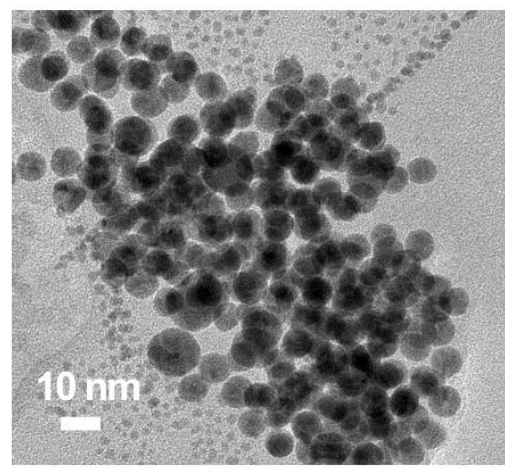

Figure S6. The UV-vis spectra of the AuNPs as a function of the $\mathrm{HAuCl}_{4}$ concentration: (a) HA and (b) SRFA, (c) the effect of the $\mathrm{HAuCl}_{4}$ concentration on the AuNP size, (d) a typical TEM image of the AuNPs using SRFA. Reaction conditions: c(HS)=100 $\mathrm{mg} \cdot \mathrm{L}^{-1}, \mathrm{c}(\mathrm{NaOH})=4-8 \mathrm{mM}$ (depending on concentration of $\mathrm{HAuCl}_{4}$, final $\mathrm{pH}=10$ ), $\mathrm{c}\left(\mathrm{HAuCl}_{4}\right)=0.5-3 \mathrm{mM}, \mathrm{T}=100^{\circ} \mathrm{C}, \mathrm{t}=40 \mathrm{~min}$. The error bars represent the standard deviations for three replicates. 

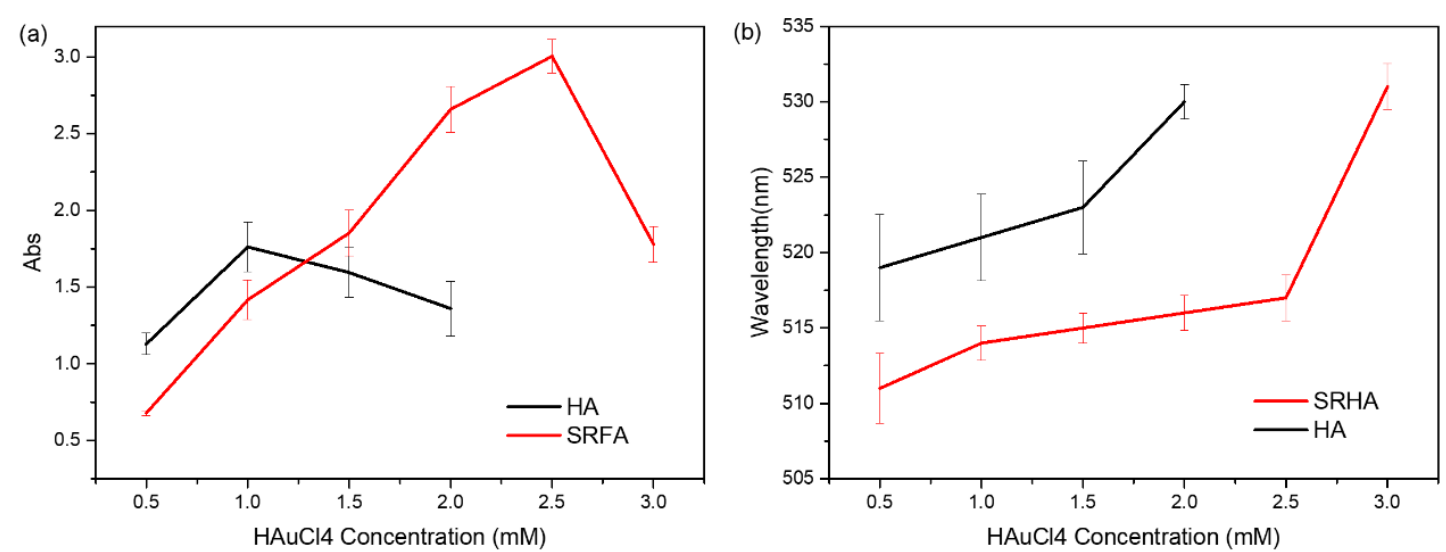

Figure S7. Effect of $\mathrm{HAuCl}_{4}$ concentration on (a) the absorbance intensity and (b) the maximum absorbance wavelength of AuNPs. The error bars represent the standard deviations for three replicates.

(a)

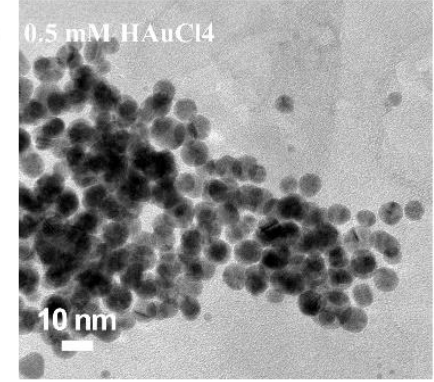

(d)

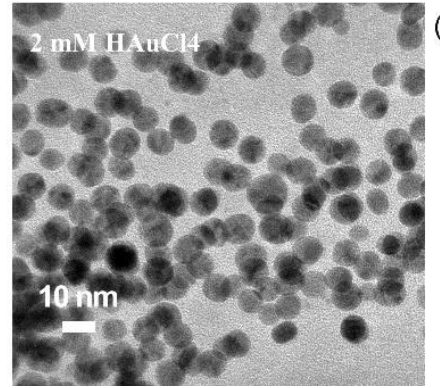

(b)

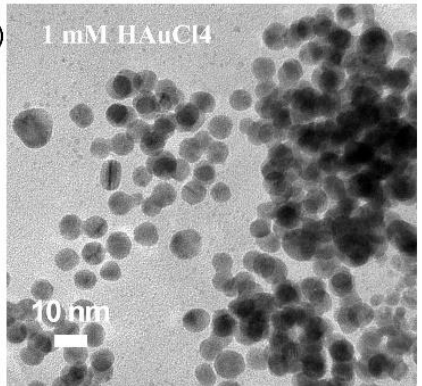

(e)

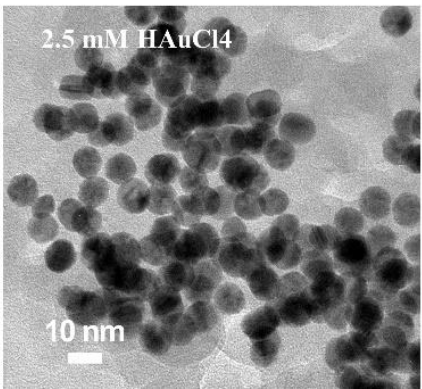

(c)

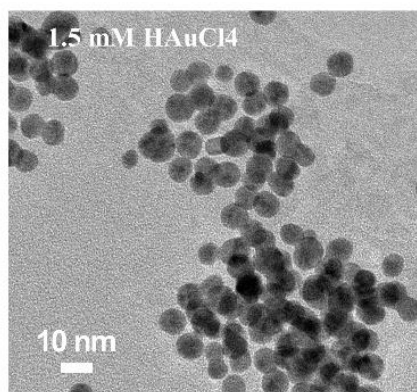

(f)

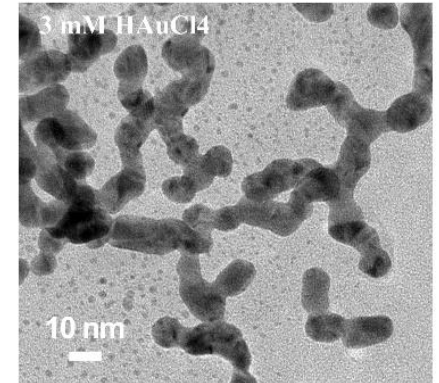

Figure S8. TEM images of the AuNPs as a function of $\mathrm{HAuCl}_{4}$ concentration. Reduction condition: $c(\mathrm{SRFA})=100 \mathrm{mg} \cdot \mathrm{L}^{-1}, \mathrm{c}(\mathrm{NaOH})=4-8 \mathrm{mM}$ (depending on concentration of $\mathrm{HAuCl}_{4}$, final $\left.\mathrm{pH}=10\right), \mathrm{T}=100^{\circ} \mathrm{C}, \mathrm{t}=40 \mathrm{~min}$. The scale bar is $10 \mathrm{~nm}$. 

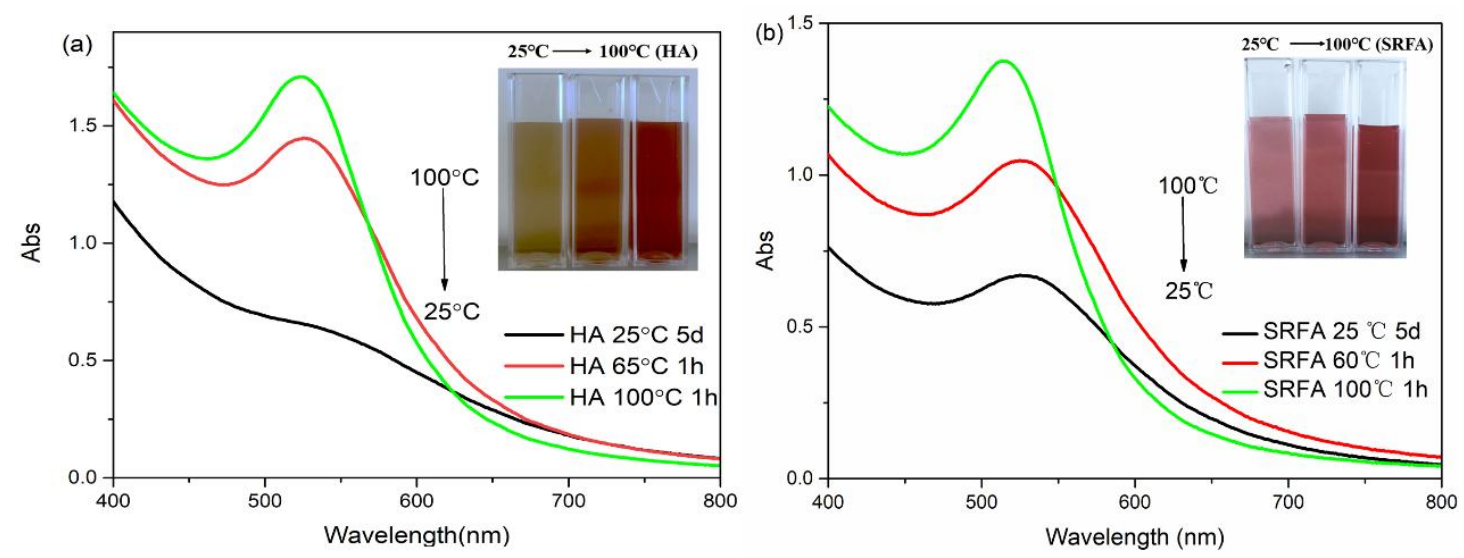

Figure S9. Effect of heating temperature on the formation of AuNPs. Reduction condition: $\mathrm{c}(\mathrm{SRFA})=100 \mathrm{mg} \cdot \mathrm{L}^{-1}, \mathrm{c}\left(\mathrm{HAuCl}_{4}\right)=1 \mathrm{mM}, \mathrm{c}(\mathrm{NaOH})=4 \mathrm{mM}$ (in the final solution).

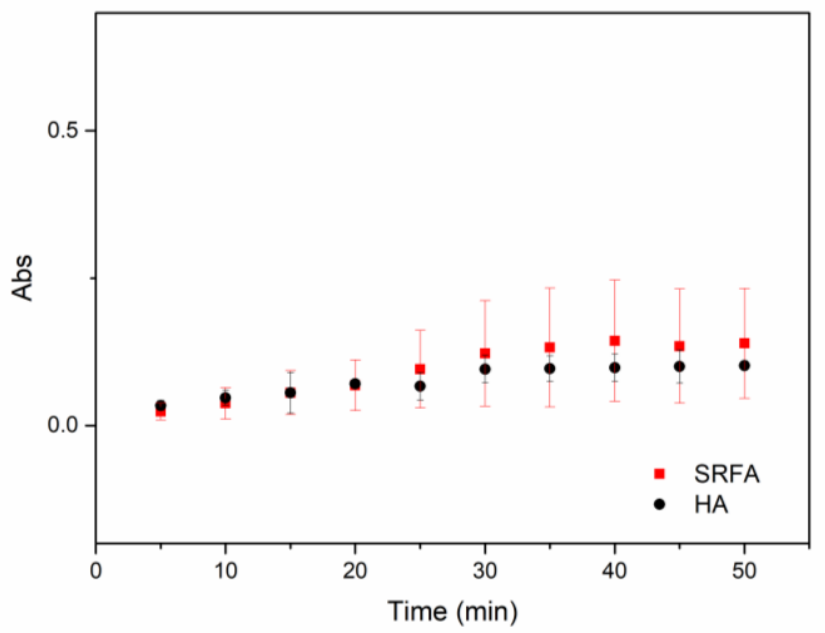

Figure S10. Time-resolved evolution of absorption of AuNPs. c(HS)=100 mg $\cdot \mathrm{L}^{-1}$, $\mathrm{c}\left(\mathrm{HAuCl}_{4}\right)=1 \mathrm{mM}, \mathrm{c}(\mathrm{NaOH})=4 \mathrm{mM}$ (in the final solution), $\mathrm{T}=100{ }^{\circ} \mathrm{C}$. The error bars represent the standard deviations for three replicates. 

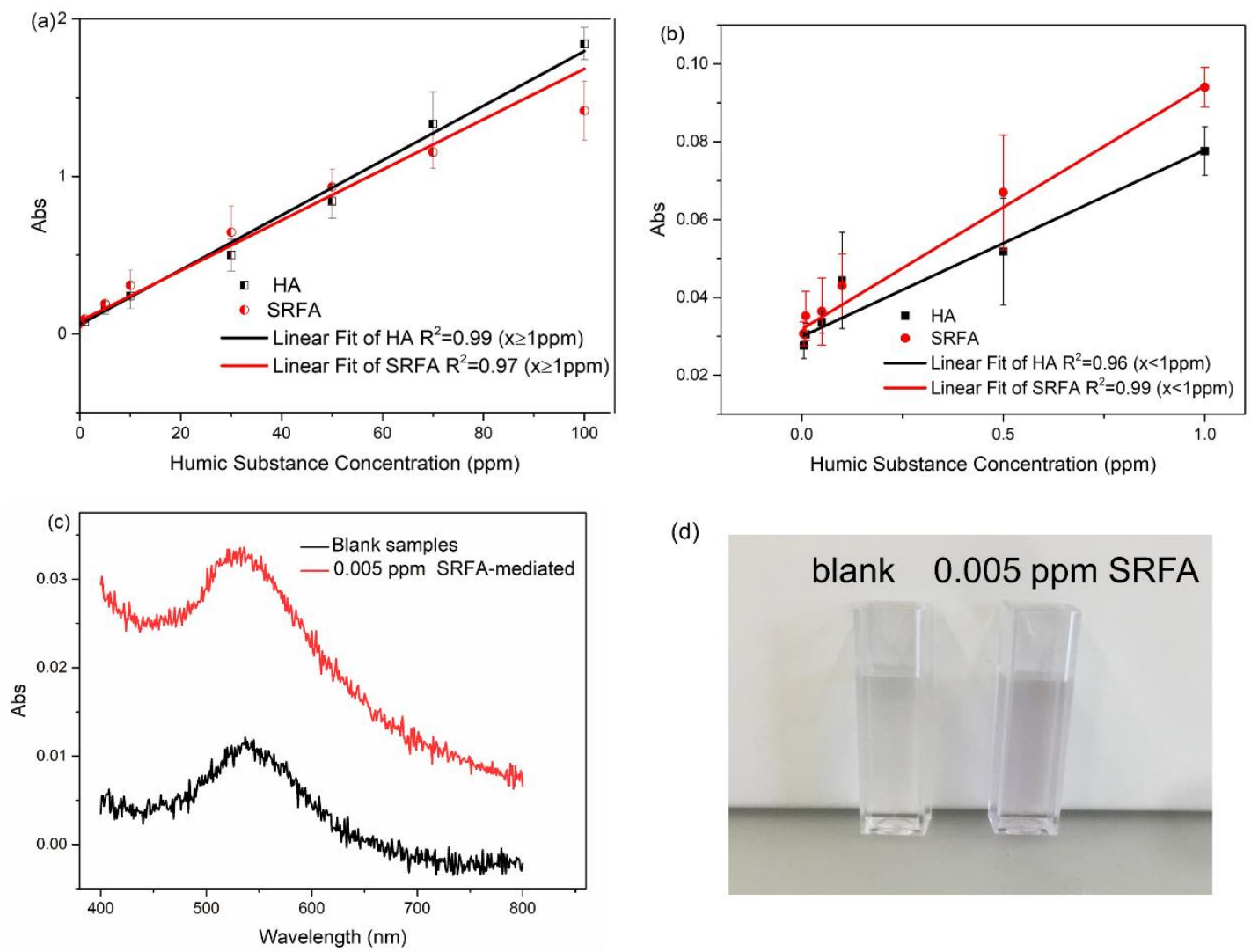

(d)

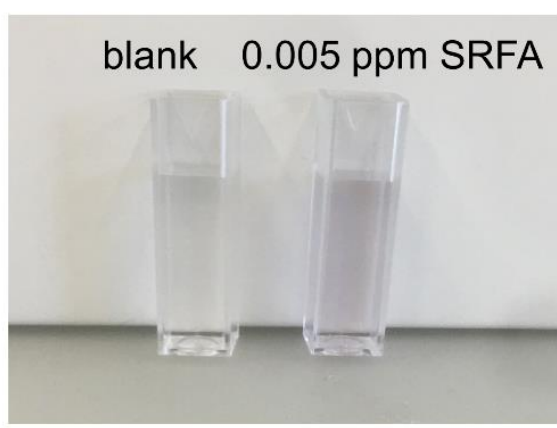

Figure S11. Calibration curve (a) and (b) corresponding to HA and SRFA ranging from $0.005 \mathrm{ppm}$ to $100 \mathrm{ppm}$. The error bars represent the standard deviations for three replicates. (c) the absorption spectra and (d) photograph about the blank samples and 0.005 ppm SRFA-mediated AuNPs. 

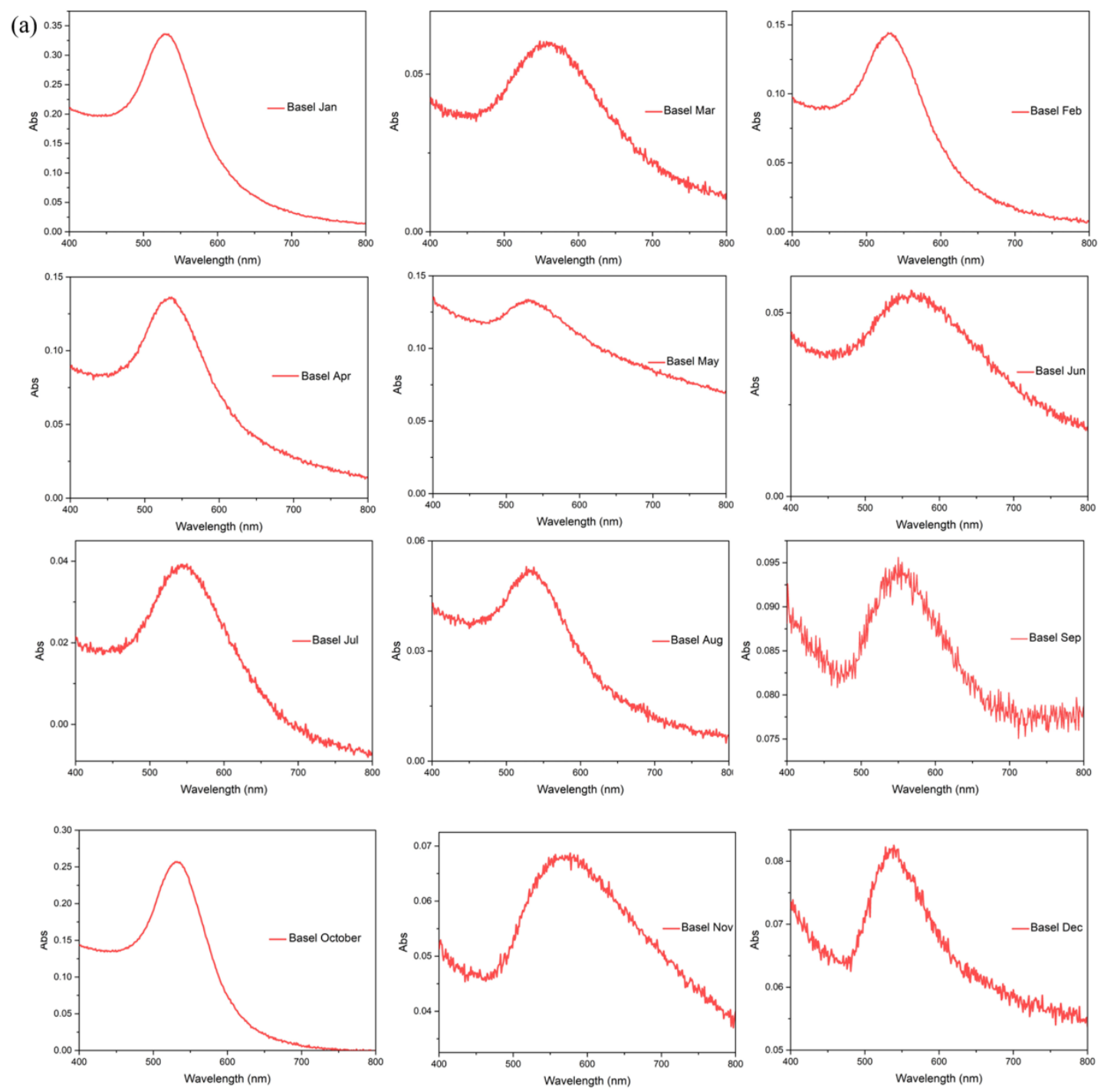
(b)
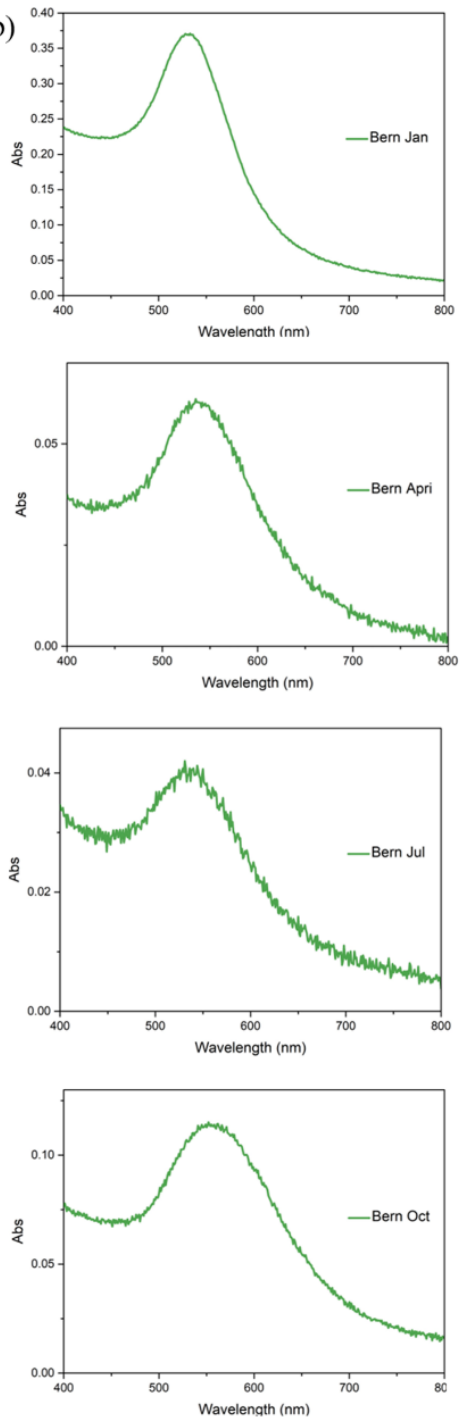
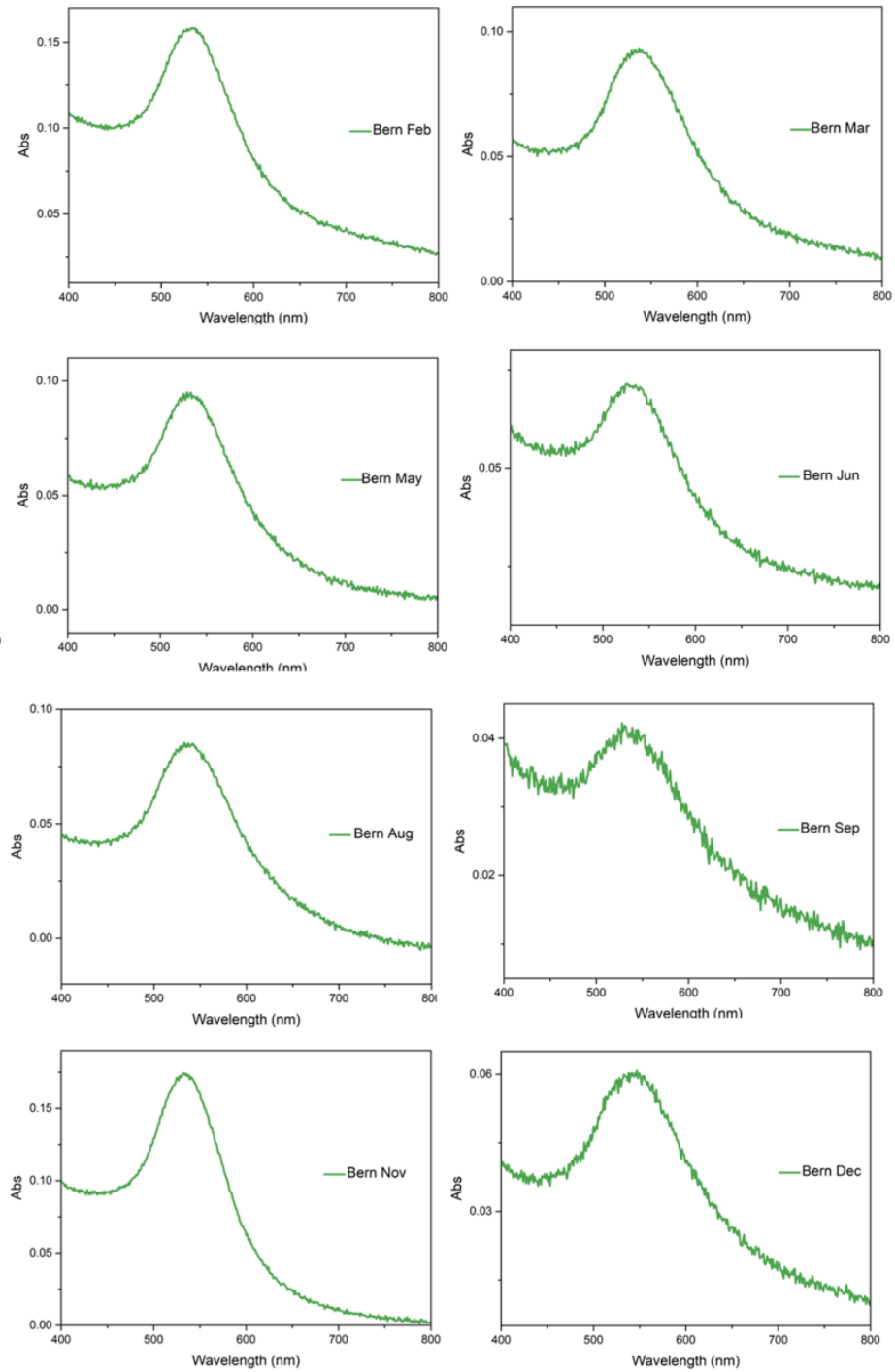

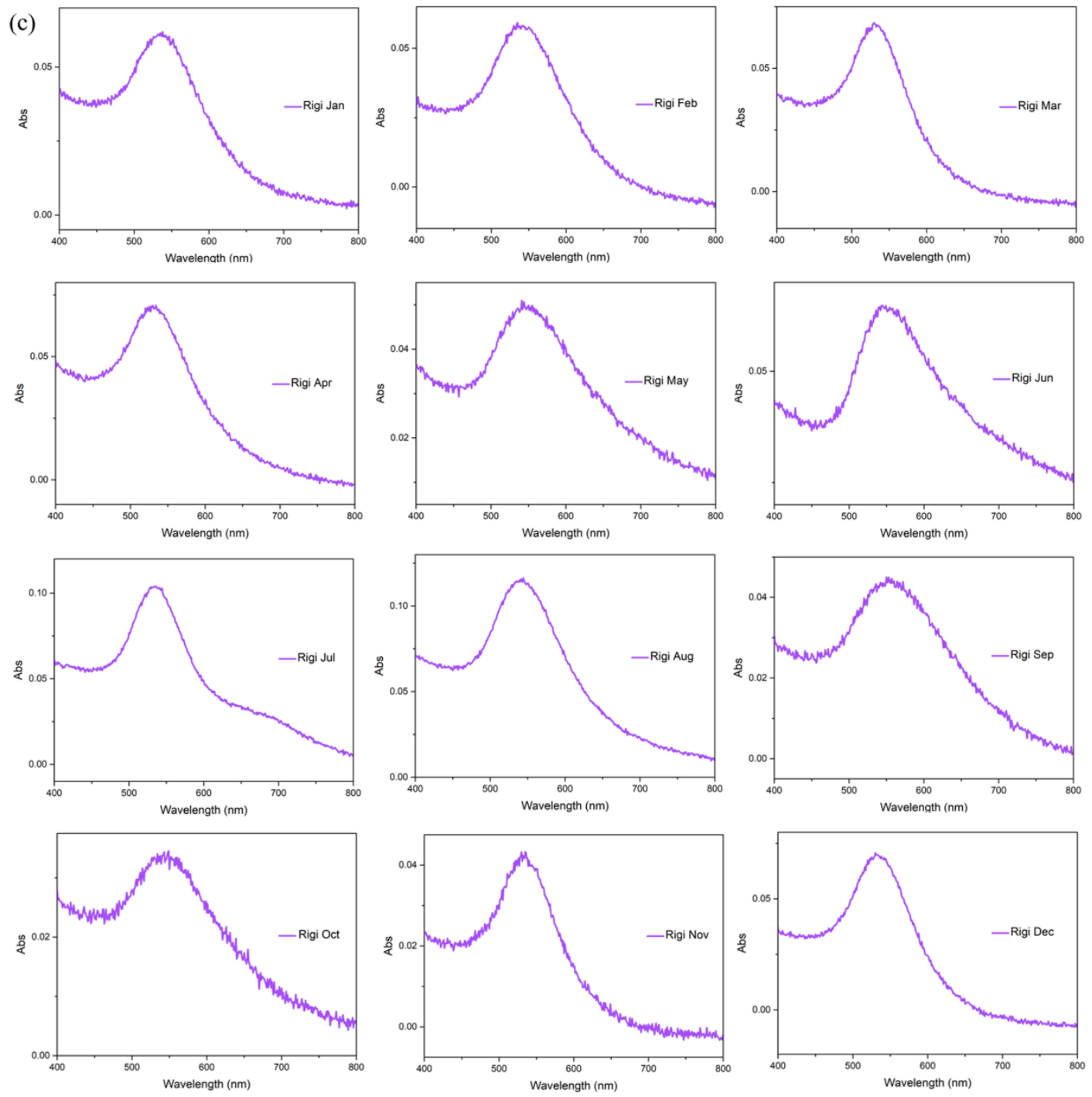

Figure S12. The absorption spectra toward the monthly samples from (a) Basel, (b) Bern, (c) Rigi sampled from Jan 2017 to Dec 2017. 

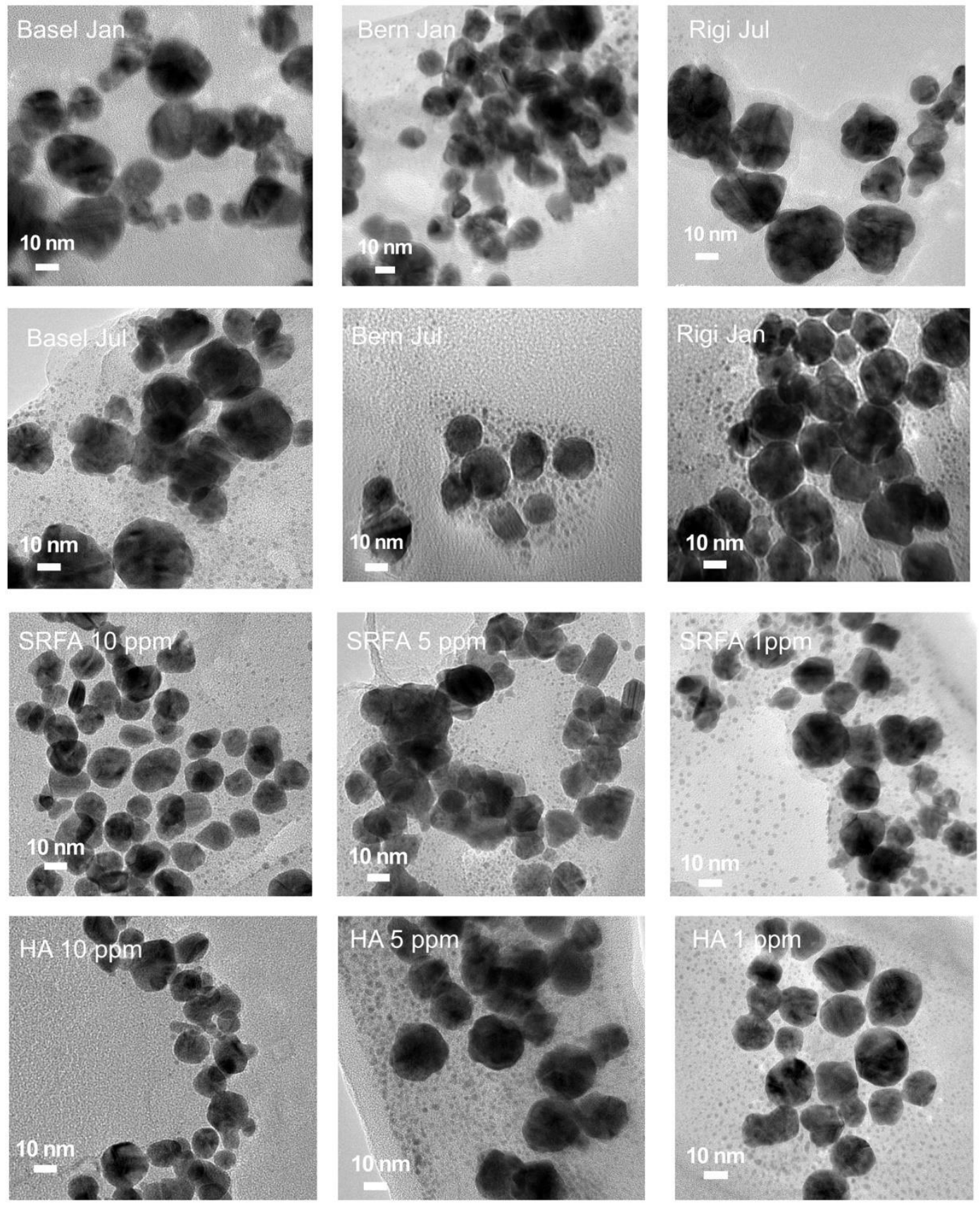

Figure S13. TEM images of the AuNPs formed by Basel, Bern, Rigi Mountain and HS, the scale bar is $10 \mathrm{~nm}$. 


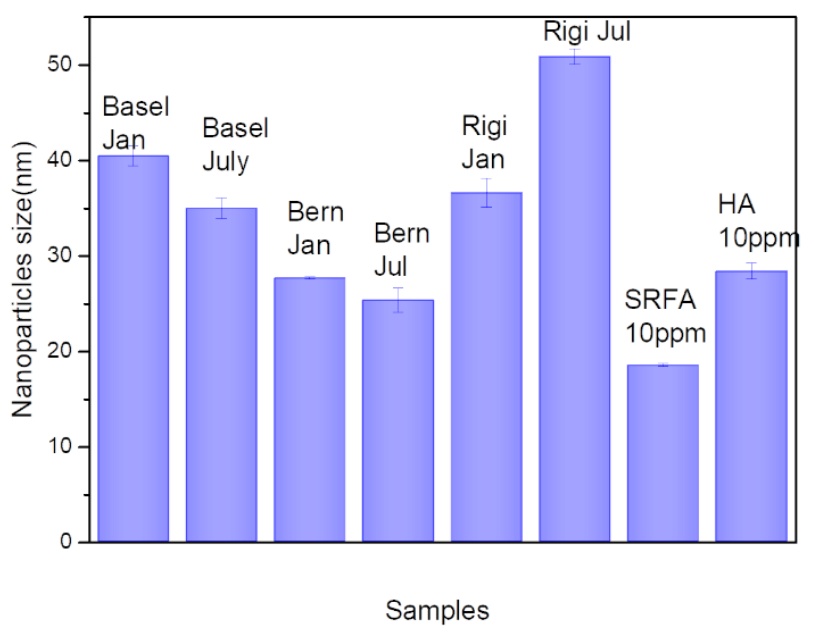

Figure S14. The hydrodynamic size of AuNPs prepared by real-world environmental samples and HS.

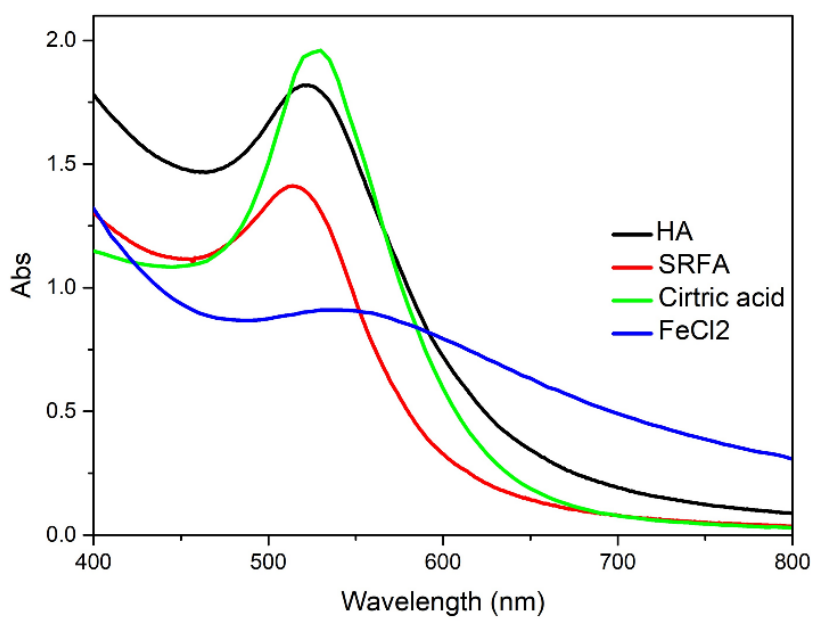

Figure S15. Comparison of AuNPs intensity in the condition of four reductants. Reduction condition: $\mathrm{c}($ reductant $)=100 \mathrm{mg} \cdot \mathrm{L}^{-1}, \mathrm{c}\left(\mathrm{HAuCl}_{4}\right)=1 \mathrm{mM}, \mathrm{c}(\mathrm{NaOH})=4-8 \mathrm{mM}$ ( $\mathrm{pH}=10$ in the final solution), $\mathrm{T}=100{ }^{\circ} \mathrm{C}, \mathrm{t}=40 \mathrm{~min}$. 
Table S1 The responses data for LOD and LOQ calculation.

\begin{tabular}{lllll}
\hline Number & $\begin{array}{l}\text { Concentration } \\
(\mathrm{ppm})\end{array}$ & $\begin{array}{l}\text { Absorption } \\
\text { intensity }\end{array}$ & $\begin{array}{l}\text { Standard } \\
\text { deviation }\end{array}$ & Signal/ Noise \\
\hline 1 & 0.005 & 0.0307 & 0.0031 & 4.3921 \\
2 & 0.01 & 0.0353 & 0.0063 & 5.3755 \\
3 & 0.05 & 0.0364 & 0.0086 & 5.6223 \\
4 & 0.1 & 0.0430 & 0.0082 & 7.0384 \\
5 & 0.5 & 0.0670 & 0.0147 & 12.1888 \\
6 & 1 & 0.0940 & 0.051 & 17.9826 \\
\hline
\end{tabular}

Table S2 Analytical figures of merit of calibration with HA and SRFA

\begin{tabular}{ccc}
\hline Parameter & HA & SRFA \\
\hline & $y=0.01735 x+0.06034$ & $y=0.01586 x+0.08184$ \\
Calibration equation & $(x \geqslant 1 \mathrm{ppm})$ & $(x \geqslant 1 \mathrm{ppm})$ \\
& $y=0.04793 \mathrm{x}+0.02995$ & $y=0.06258 x+0.03187$ \\
Regression coefficient & $(x<1 \mathrm{ppm})$ & $(x<1 \mathrm{ppm})$ \\
Linear range $(\mathrm{ppm})$ & 0.995 and 0.968 & 0.965 and 0.990 \\
LOD $(\mathrm{ppm})$ & $0.005-100$ & $0.005-100$ \\
& 0.005 & 0.005 \\
\hline
\end{tabular}

\section{References}

(1) Casado, A. G.; Rodriguez, L. C.; Hernandez, E. A.; Vilchez, J. L. Estimate of gas chromatographic blanks - Application to detection limits evaluation as recommended by IUPAC, J. Chromatogr. A 1996, 726, 133-139. 